\title{
As variedades linguísticas no livro didático Português - linguagens: uma abordagem sociolinguística
}

\section{Linguistic varieties in the educational book Português - linguagens: a sociolinguistic approach}

Antônio Flávio Ferreira de Oliveira ${ }^{1}$, Ilderlândio Assis de Andrade Nascimento²

Doutorando em Linguística pelo Programa de Pós-

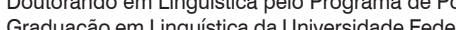
da Parába - PROLING/UFPB e bolsista da CAPES. E-mail: flavioccaa@hotmail.com Doutorando em Linguística pelo Programa de PósGraduação em Linguística da Universidade Feder da Paralla - PROL
RESUMO: 0 livro didático (re)produz ideologias linguísticas, assumindo um papel importante, já que ele é utilizado como principal recurso de ensino de Língua Portuguesa. Neste trabalho, objetivamos analisar uma proposta de ensino da variação linguística no livro didático de língua portuguesa Português: Linguagens, dos autores William Roberto Cereja e Thereza Cochar Magalhães, atentando para o modo como as variedades linguísticas são trabalhadas. Para isso, dialogamos com estudos de Labov (2008), Tarallo (2005), Hernández Campoy e Almeida (2005), Fernández (1998), Bagno (2008), Lucchesi (2015), Milroy (2011), Faraco (2008) e Moita Lopes (2013). A análise revela que ainda há uma limitação no trato com as variedades linguísticas, focalizando apenas aquelas usadas pelas populações pobres. Ademais, a proposta de ensino parte de polarizações linguístico-sociais: certo e errado, padrão e não padrão, culto e caipira, assumindo a norma padrão da língua para, a partir dela, conceituar as demais como sendo desprestigiadas, vulgares e caipiras. Esse tratamento, (re)produz e fortalece preconceitos sociais e linguísticos, já que reproduz, sem questionamentos, certos paradigmas, naturalizando, assim, a polarização sociolinguística. Fica claro, portanto, que a força da ideologia da língua padrão cria uma imagem de língua da elite, uma língua que garante a aquisição de bens simbólicos.

Palavras-chave: Livro didático; Variação linguística; Ensino; Ideologia.

ABSTRACT: The educational book (re)produces linguistic ideologies and assumes an important role, as it is used as the main resource in the Portuguese Language teaching. In this work we object to analyze a teaching proposal in the treatment given to the linguistic variation in the Portuguese Educational book Português: Linguagens of the authors William Roberto Cereja and Thereza Cochar Magalhães. In this regard, we attempt to the manner how the linguistic varieties are worked. Thus, we dialogue with the studies of Labov (2008), Tarallo (2005), Hernández Campoy and Almeida (2005), Fernández (1998), Bagno (2008), Lucchesi (2015), Milroy (2011) and Moita Lopes (2013). The analysis reveals that there is still a limitation in the treatment of linguistic varieties, and it focus only on those ones that are used by poor populations. Besides, the teaching proposal comes from the social-linguistic polarizations: the right and the wrong, the cult and the uneducated (the hick) variations. Besides, the educational book focus on the grammatical corruption as a teaching resource used for the teaching of linguistic variation and assumes the pattern norms of the language for, from it, concepting other variations as being irrelevant, vulgar and hick. This treatment (re)produces and makes strong social and linguistic prejudices, once that reproduces, without questions, some paradigms, in a specific manner, it naturalizes the sociolinguistic polarization. It is clear, however, that the ideological force of the standard language might create an image of the elite's language, one that guarantees the acquisition of symbolic benefits.

KEYWORDS: Educational book; Linguistic variation; Teaching; Ideology. 


\section{Introdução}

Língua Portuguesa não é uniforme. Ela apresenta variações, de acordo - com o meio social, geográfico ou situacional do qual o sujeito falante faz parte, sendo isso um aspecto constitutivo da natureza de todas as línguas. Nos termos de Labov (2008, p. 221), o comum na língua é que se tenha “diversas maneiras alternativas de dizer 'a mesma' coisa". Com as devidas ressalvas, essa tem sido a constatação de estudiosos da linguagem, mais precisamente daqueles que investigam as manifestações de linguagem numa perspectiva sociolinguística. No entanto, ainda é preocupante o fato de haver muitas manifestações preconceituosas acerca dos usos de certas variedades da língua na sociedade brasileira.

No âmbito educacional, o debate em torno das variedades linguísticas foi introduzido nas escolas brasileiras há muitos anos, quando o Ministério da Educação deu o aval para se trabalhar a variação linguística no livro didático de Língua Portuguesa. Assim, o livro didático teve um papel relevante no planejamento das aulas do professor de português. Diante disso, neste trabalho, objetivamos analisar uma proposta de ensino da variação em um livro didático de língua portuguesa (LDLP), mais especificamente como a variação linguística é trabalhada, uma vez que o livro didático (LD) é o principal instrumento utilizado pelos professores em sala de aula.

Nesse sentido, entendemos, juntamente com Leite (2004), que a relação entre a sociolinguística interacional e a educação é mais próxima do que se imagina. Assim, assumimos o pressuposto de que a escola é uma instituição (in)formadora, bem como (re)produtora de ideologias e crenças acerca de temas/objetos/sujeitos.

Com relação às ideologias em torno das variedades da língua, o LD assume um papel importante, já que ele é utilizado como principal recurso de ensino de Língua Portuguesa. Nesse caso, entendemos que o LD transmite, juntamente com certos conhecimentos sobre a língua, ideologias/crenças que, muitas vezes, são passadas para os alunos sem uma reflexão crítica. Como bem salienta Antunes (2007, p. 112), "vale o que eles dizem, o que eles prescrevem. Eles, os manuais, é que mandam." Nessa perspectiva de ensino, os alunos e professores ficam reféns dos autores desses manuais.

Tendo isso em vista, analisamos uma proposta de ensino do livro didático (LD) Português: Linguagens, dos autores William Roberto Cereja e Thereza Cochar Magalhães, da editora Atual, 2009, especificamente o volume trabalhado no 6을 (sexto) ano do Ensino Fundamental. Mais precisamente, analisaremos as seções de formulações conceituais e, em seguida, duas atividades destinadas ao tratamento da variedade linguística.

As discussões empreendidas aqui partem, entre outros, dos estudos de Labov (2008), considerado o principal nome dos estudos sociolinguísticos, por seu trabalho fundador. Entre outros, dialogamos, ainda, com Tarallo (2005), que faz uma retomada pertinente das principais noções da sociolinguística, e com Bagno (2008), que aborda os preconceitos relacionados aos usos de certas variedades da língua. Além desses, na mesma linha, retomamos o pertinente estudo de Lucchesi (2015) que aborda a relação entre língua e sociedade, mostrando a construção da polarização sociolinguística do Brasil. Não menos importante, visando mostrar as ideologias/crenças, muitas vezes preconceituosas, em torno de certos usos linguísticos, traremos para discussão Milroy (2011) e Moita Lopes (2013).

Dito isso, discutiremos, na primeira seção deste trabalho, acerca da Sociolinguística como área da ciência da linguagem que coloca um foco especial nos usos sociais da língua; na segunda seção, apresentaremos discussões em torno das variedades linguísticas, ressaltando ideologias e preconceitos que acompanham certos usos da língua; na terceira seção, voltamos nosso olhar para o livro didático, objetivando perceber como se dá o tratamento das variedades linguísticas. Por fim, para efeito de conclusão, 
destacaremos alguns aspectos importantes das análises e faremos alguns apontamentos necessários para que seja compreendida a nossa proposta de pesquisa.

\section{Da Sociolinguística: o foco nos usos sociais da língua}

De acordo com Hernández Campoy e Almeida (2005, p. 1), “a Sociolinguística é uma ciência interdisciplinar que se ocupa das relações existentes entre a linguagem e a sociedade". Contudo, esta definição, apesar de apresentar pontos relevantes sobre a disciplina, não constitui uma definição abrangente nem efetiva quanto à uma verdade final. De modo mais abrangente, de acordo com os autores mencionados, podemos dizer que a definição dessa ciência problematiza possíveis pontos de vista, que estão relacionados a ser uma disciplina com uma identidade peculiar, a ser interdisciplinar, bem como a ser uma ramificação da linguística.

Sobre a problematização dos pontos de vista relacionados à Sociolinguística, podemos inferir que, se essa ciência for considerada como uma disciplina com uma identidade peculiar e característica às particularidades de sua própria natureza, sua definição será estabelecida a partir das diretrizes que constituem um método próprio para o tratamento dos fatos de linguagem, recorrentes no seu vasto campo de conhecimento.

Por outro lado, se essa ciência for considerada como uma disciplina com tendência interdisciplinar, sua definição se estenderá e se fará a partir de elementos metodológicos constituídos nos diversos campos de conhecimento que consolidam a interdisciplinaridade. Por último, se essa ciência for compreendida como uma ramificação da linguística, sua definição pode ser estabelecida a partir dos elementos que constituem a natureza metodológica usada para abordar os fatos de linguagem tratados pela linguística propriamente dita. Sendo assim, não é tão fácil encontrar uma definição exata que contemple todas as possibilidades de abrangência de objetos a serem investigados por essa ciência pluralizada.

Esse posicionamento nos faz entender que a mobilização na apreensão desse campo de conhecimento está relacionada à natureza heterogênea da linguagem como um produto da convenção social, bem como uma capacidade peculiar que o indivíduo tem para expressar a fala. Dessa maneira, cruzam-se, na abrangência da natureza conceptual da Sociolinguística, fatores ligados à cognição, à historicidade, à ideologia, à cultura, à linguística propriamente dita, dentre outros aspectos.

Em relação ao posicionamento que estabelece os usos sociais da língua, queremos tomar como referência: (a) o posicionamento de Hernández Campoy e Almeida (2005, mencionado em supradito, que compreende a interdisciplinaridade nas relações entre língua e sociedade; e o (b) posicionamento de Labov (2008), o qual compreende que a linguagem acontece nas intermediações dos contextos sociais.

No campo da linguagem e da Sociolinguística, não podemos falar da noção de uso, sem consideramos a importância da interdisciplinaridade na relação língua-sociedade-contexto. Nesse ínterim, além dos fatos concernentes às relações de funcionamento interno do sistema linguístico (fatos relacionados à Fonologia, Morfologia, Sintaxe e à Semântica), passam a existir outros fatos que, fora do núcleo linguístico, mobilizam conhecimentos relacionados à Estilística, à Psicolinguística, à Pragmática, à Etnografia, à Sociologia, à Análise do discurso, dentre outros.

A imbricação dos fatos interior e exterior à linguagem constituem forças linguístico-sociais capazes de estender o campo de uso da linguagem humana para além das fronteiras isoladas da linguística. Desse modo, nos domínios da interdisciplinaridade, o uso da linguagem se faz por meio de diversos elementos apreendidos pela força da cultura, da história, da ideologia, da Sociologia, da Etnografia, e da própria linguagem. 
O foco no uso social da língua, de acordo com Hernández Campoy e Almeida (2005) compreende as seguintes características: (a) a língua serve as necessidades dos seres humanos, sendo um instrumento de interação social; (b) existe uma competência comunicativa que o sujeito tem para interagir socialmente através da linguagem; (c) existem cenários onde a interação linguística acontece; e, por fim, (d) existem objetivos para que aconteça a comunicação.

Portanto, pensar na Sociolinguística como uma ciência constituída pelos elementos linguísticos e pelos elementos da interdisciplinaridade, requer considerar que os elementos constituintes dessa ciência compreendem a relação entre as forças sociais e estruturais da língua. Desse modo, o sujeito falante de uma determinada variedade linguística constrói a sua fala, atravessado por elementos linguísticos e sociais, indispensáveis na produção da comunicação nos diversos cenários sociais.

\section{Variedades linguísticas e variedades sociais: ideologias e preconceitos}

Um pressuposto fundamental na abordagem laboviana é o que postula a variação como fato inerente às línguas que estão ligadas diretamente à noção de heterogeneidade - as línguas são sistemas heterogêneos (e não homogêneos, conforme postulam Saussure e Chomsky). A variação é inerente às línguas, e não compromete o bom funcionamento do sistema linguístico nem a possibilidade de comunicação entre falantes. A existência de variedades nas línguas, ao contrário, em vez de comprometer o mútuo entendimento, é rica em significado social. Na perspectiva laboviana, a variação é um fenômeno que engloba o nível fonológico, bem como o morfológico, o sintático, o lexical e o discursivo.

A partir dos estudos de Labov, percebemos que, em um certo sentido, as variedades da língua, as formas diferentes que empregamos ao falar e ao escrever, dizem quem somos: dão pistas a quem nos ouve ou lê sobre (i) o local de onde viemos, (ii) o quanto estamos inseridos na cultura letrada dominante de nossa sociedade, (iii) quando nascemos, (iv) com que grupo nos identificamos, entre várias outras informações.

Ainda, quanto ao conceito de variação linguística, Fernández (1998, p. 17, tradução nossa) explica que os estudiosos da Sociolinguística denominam de variação linguística os casos em que "o uso de um elemento em lugar de outro do mesmo nível não supõe nenhum tipo de alteração semântica: tanto se usa um como se usa o outro, se está dizendo o mesmo". O autor especifica a diferença entre variável e variante. Uma variável linguística é um conjunto de expressões de um mesmo elemento e cada uma das manifestações ou expressões de uma variável recebe o nome de variante linguística.

Ademais, cabe assinalar a existência de fatores linguísticos e extralinguísticos envolvidos no fenômeno da variação. Os fatores linguísticos podem ser, por exemplo, a colocação de um certo elemento na palavra, ou até mesmo a ausência de elementos. Já os fatores extralinguísticos compreendem aspectos como idade, escolaridade, classe social, profissão, situação comunicativa. Quanto ao modo de determinação desses fatores no fenômeno da variação, Fernández (1998, p. 31, tradução nossa) sugere o seguinte:

a variação fonético-fonológica e a do tipo morfológico e funcional vêm determinadas frequentemente por fatores linguísticos e extralinguísticos, a variação categorial e posicional (sintática) vem explicada majoritariamente por fatores linguísticos e a variação lexical, por fatores extralinguísticos.

O autor em questão ressalta, no entanto, que não é possível conhecer de antemão que tipo de variáveis sociais vão atuar sobre os elementos linguísticos em uma dada comunidade de fala. Isso acontece porque, 
primeiro, os fatores sociais atuam sobre a língua de maneira irregular, o quer dizer que um mesmo fator social pode produzir diferentes variantes linguísticas em diferentes comunidades de fala e, segundo, os fatores sociais não estão configurados de formas idênticas em todas as comunidades.

Nesse sentido, é importante destacar a noção de estratificação social que, segundo Labov (2008), é o produto da diferenciação social e da avaliação social. Isso implica dizer que, no entender desse autor, "os mecanismos usuais da sociedade produziram diferenças sistemáticas entre certas instituições ou pessoas, e que essas formas diferenciadas foram hierarquizadas em status ou prestígio por acordo geral" (LABOV, 2008, p. 65). Logo, sujeitos de determinada estratificação social podem usar a mesma variedade da língua. Os usos das variedades linguísticas, assim, acompanham as estratificações da sociedade. Com isso, percebemos a relação inseparável entre língua e fatores socioculturais.

A variação é um fato, mas algumas variantes costumam receber valores distintos por parte da comunidade. No caso do Brasil, por exemplo, geralmente se define todas as outras variedades tendo como critério a chamada variante padrão. Essa variante é aquela que condiz com as prescrições dos manuais de norma padrão. Já as variantes não-padrão se afastam desse modelo. Embora a variante padrão não seja a mais usada por uma comunidade é, em geral, a variante de prestigio, enquanto a não-padrão é muitas vezes estigmatizada. Isso pode ser percebido a partir dos comentários negativos à forma ou aos falantes que a empregam.

Cabe ressaltar a distinção entre norma culta e norma-padrão. A primeira designa o conjunto de fenômenos linguísticos que ocorrem habitualmente no uso dos falantes letrados em situações mais monitoradas de fala e escrita. Já a norma-padrão "é uma codificação relativamente abstrata, uma baliza extraída do uso real para servir de referência, em sociedades marcadas por acentuada dialetação, a projetos políticos de uniformização linguística", conforme explicação de Faraco (2008, p. 73). Portanto, a norma-padrão não é, conforme defende o autor, uma variedade da língua, mas um construto sócio-histórico.

A noção de norma nos estudos linguísticos, na perspectiva do referido autor, não se limita a uma variedade correta da língua. Ele argumenta que o termo norma é usado para designar os fatos de língua usuais, comuns, correntes numa determinada comunidade de fala. Ou seja, "norma designa o conjunto de fatos linguísticos que caracterizam o modo como normalmente falam as pessoas de uma certa comunidade, incluindo os fenômenos em variação" (FARACO, 2008, p. 40).

Nessa perspectiva, a norma distingue e é constitutiva de grupos sociais e situações comunicativas, constituindo-se fator de identificação de grupos. Desse modo, levando em conta que um mesmo indivíduo participa de grupos sociais diferentes e de diferentes situações comunicativas, esse indivíduo, segundo Faraco (2008, p. 41), “domina mais de uma norma (já que a comunidade sociolinguística a que pertence tem várias normas) e mudará sua forma de falar (sua norma) variavelmente de acordo com as redes de atividades e relacionamentos em que se situa". É essa relação intrínseca entre uso linguístico (certa norma) e as práticas sociais de uso que coloca a compreensão de norma não apenas enquanto conjunto de formas linguísticas, mas principalmente enquanto "agregado de valores socioculturais articulados com aquelas normas" (FARACO, 2008, p. 41).

$\mathrm{Na}$ trilha dos estudos labovianos, Tarallo (2007) explicita a noção de variável e variantes linguísticas. Segundo ele, dá-se o nome de variantes às formas em variação, ou melhor, variantes são as diversas maneiras de se dizer a mesma coisa em um mesmo contexto, ou com o mesmo valor de verdade. Por sua vez, a variável linguística seria o conjunto de variantes. 
Tarallo (2007) aponta para o fato de que as variantes linguísticas, em uma determinada sociedade e em determinado momento histórico, estão sempre em relação de concorrência: padrão versus não-padrão; conservadoras versus inovadoras; de prestígio versus estigmatizadas. Segundo o autor:

a variante padrão é, ao mesmo tempo, conservadora e aquela que goza do prestígio sociolinguístico na comunidade. As variantes inovadoras, por outro lado, são quase sempre não-padrão e estigmatizadas pelos membros da comunidade (TARALLO, 2007, p. 12).

Essa concorrência, geralmente, está atrelada a preconceitos. Ao se dedicar ao estudo dos principais preconceitos linguísticos no Brasil, Bagno (2008) aponta alguns meios que os alimentam:

[...] o que vemos é esse preconceito ser alimentado diariamente em programas de televisão e de rádio, em colunas de jornal e revista, em livros e manuais que pretendem ensinar o que é 'certo' e o que é 'errado', sem falar, é claro, nos instrumentos tradicionais de ensino da língua: as gramáticas normativas e boa parte dos livros didáticos disponíveis no mercado. (BAGNO, 2008, p. 23)

O preconceito linguístico está enraizado na cultura brasileira. Ele é perverso tanto quanto qualquer um outro tipo de preconceito. No entanto, o que se percebe, ao contrário do que ocorre com os demais tipos de preconceitos, é que não existe um esforço para acabar com o preconceito linguístico. Isso só evidencia o poder do preconceito linguístico, já que ele é, conforme Bagno (2008, p. 23), "invisível, no sentido de que quase ninguém se apercebe dele, quase ninguém fala dele, com exceção dos raros cientistas sociais que se dedicam a estudá-lo".

Bagno (2008) lista oito mitos em torno da língua portuguesa, a saber: (1) A língua portuguesa falada no Brasil apresenta uma unidade surpreen- dente - Este é o maior e o mais sério de todos os mitos, pois ele não admite variação -; (2) Brasileiro não sabe português/só em Portugal se fala bem português - algumas pessoas acreditam nesse mito devido às influências culturais deixadas pelos portugueses durante a colonização -; (3) Português é muito difícil - a língua aqui é reduzida às regras gramaticais, assim, os falantes da Língua Portuguesa dizem que a língua nativa é muito difícil, pelo simples fato da gramática ser composta por várias regras que poucos conseguem dominar com desenvoltura -; (4) As pessoas sem instrução falam tudo errado - nesse mito, a língua envolve um 'triângulo escola-gramáticadicionário', ou seja, a fala dessas pessoas é considerada 'erro' pelo fato de elas não terem instrução escolar e não seguirem as normas gramaticais -; (5) O lugar onde se fala melhor português no Brasil é no Maranhão para esse mito, a linguagem utilizada no Maranhão segue os parâmetros do português clássico que utilizava o pronome 'tu', por isso, devido às nossas heranças culturais presentes na língua deixada pelos portugueses, acredita-se que onde se fala melhor português é no Maranhão, no entanto, não existe variação melhor ou pior que outra -; (6) 0 certo é falar assim porque se escreve assim - nesse mito, a língua escrita não admite variações, ela é a base para falarmos sempre 'correto', com isso, estamos presos à ideia de que tudo que não for falado conforme a língua escrita é 'errado' - ; (7) É preciso saber gramática para falar e escrever bem - este mito é valorizado por pessoas que acreditam que a gramática é o único e verdadeiro caminho para que os alunos possam escrever e falar 'corretamente'; (8) O domínio da norma culta é um instrumento de ascensão social - esse é mais um mito sem fundamento, pois, se fosse assim, todas as pessoas tentariam ser professores ou professoras de português, já que supomos que eles compreendem a norma culta, segundo Bagno.

Como bem salienta Bagno (2008), percebemos que todos os mitos estão ligados mais ao social, ou seja, à questão das diferenças sociais presentes na 
sociedade. $\mathrm{O}$ autor em questão chega a dizer que o preconceito linguístico não existe, o que existe de fato, é um profundo e entranhado preconceito social, ou seja, já que a sociedade brasileira só valoriza o falar das pessoas que são da alta sociedade, então o que esta classe social fala é tido como correto. É nesse sentido que o preconceito é social e não linguístico.

Ao discorrer sobre as ideologias linguísticas e as consequências da padronização, Milroy (2011) comenta que, de fato, as variedades linguísticas não têm prestígio em si mesmas, mas o adquirem quando seus falantes têm prestígio elevado, porque "o prestígio é atribuído pelos seres humanos a determinados grupos sociais e a objetos inanimados ou abstratos" (MILROY, 2011, p. 53). Para esse mesmo autor, a padronização consiste na imposição de uniformidade a uma classe de objetos. Logo, a padronização da língua, não fugindo à regra, consiste na imposição de uma variedade da língua como a única, a correta, a perfeita.

Assim, a língua padrão se apresenta como parâmetro, como centro a partir do qual circulam todas as outras variedades linguísticas. Na metáfora utilizada por Milroy (2011, p. 57), "os dialetos se tornam, por assim dizer, satélites que têm órbitas em distâncias variadas em torno de um corpo central - o padrão". Nesse caso, na ocorrência de duas variedades da língua, a ideologia da língua padrão determina que apenas uma delas pode ser a correta, a errada deve ser evitada, com riscos de punições para aqueles que a usarem.

Milroy (2011) exemplifica isso, a partir das sentenças 'eu vi ela' e 'eu a vi'. Numa cultura de língua padrão, a primeira ocorrência está incorreta e não pode ser aceita. Quem utilizar tal variedade pode sofrer avaliações do tipo: 'não conhece o português', 'não sabe falar', 'é um assassino da língua', dentre outros. Por outro lado, a segunda variedade é a correta e dever ser ensinada. Aquele que a usa é avaliado, positivamente, como: 'conhecedor do português', 'culto', 'letrado', 'inteligente', dentre outros.
Na cultura da língua padrão, o poder da ideologia da língua padrão geralmente domina a opinião pública sobre os temas acerca da língua/ linguagem. Tal poder forma o a crença de que a língua é algo que os falantes nativos não possuem. É preciso dar a eles a língua correta, é preciso ensinar a língua pura e a escola é o lugar onde se aprende a língua verdadeira.

Ainda, acerca da ideologia linguística, Moita Lopes (2013, p. 20), por sua vez, argumenta que essa noção envolve:

tanto os modelos socioculturais da linguagem em uso, do que chamamos de português no nosso caso, construídos pelos falantes, escritores, etc., como também aqueles elaborados por especialistas do campo dos estudos da linguagem.

Ele destaca que as ideologias linguísticas advêm de perspectivas políticas, culturais e econômicas específicas. Assim, as crenças acerca da língua não podem ser entendidas sem considerar os fatores sócio-histórico-culturais responsáveis pela formação ideológica dos falantes.

Ainda, partindo dos estudos de Kroskrity (2004), Moita Lopes (2013, p. 23) elenca cinco dimensões da noção de ideologia linguística:

As ideologias linguísticas refletem os interesses de um grupo social e cultural específico (a ideologia linguística da norma, por exemplo).

1. As ideologias linguísticas são variadas, já que os significados sociais se referem a uma multiplicidade de divisões sociais de gênero, classe social, geração, sexualidade, nacionalidade, etc., que de fato se entrecortam (as ideologias linguísticas feministas, por exemplo).

2. A consciência que os participantes de um grupo específico têm das ideologias linguísticas que adotam é variável, ou seja, nem sempre os participantes demonstram consciência explícita das ideologias linguísticas que geram seus usos. 
3. As ideologias linguísticas fazem a mediação entre as estruturas sociais e a linguagem em uso.

4. Ideologias linguísticas são usadas na construção de identidades culturais e nacionais, tais como nacionalidade e etnia - os conceitos de nação, etnia e de pertencimento a um grupo dependem crucialmente dessa dimensão.

5. Na mesma linha, Lucchesi (2015) critica o mito da ameaça à unidade linguística. Esse mito consiste no seguinte: "se não houver uma rígida uniformização, a unidade da língua se perde; se o caos da variação linguística não for controlado, a comunicação verbal ficará irremediavelmente comprometida" (LUCCHESI, 2015, p. 17). Nessa concepção, a língua é dissociada dos seus usuários, sendo esses quem, de fato, garantem a unidade da língua nas interações. Conforme entende Lucchesi (2015), é exatamente a heterogeneidade da língua que garante a sua funcionalidade em uma sociedade estratificada e culturalmente diversa. Ele comenta:

É a flexibilidade conferida pela variação linguística que permite a uma mesma língua funcionar tanto nas feiras livres quanto nas sessões dos tribunais de justiça. Se fosse um código monolítico e inflexível, como sugere os puristas, a língua não poderia funcionar em ambientes culturais tão diversos, o que levaria fatalmente à sua divisão e fragmentação. (LUCCHESI, 2015, p. 17).

Conforme esse entendimento, as variedades linguísticas acompanham as variedades de situações de uso, os vários estratos sociais, as diversas situações comunicativas. A variação linguística é um aspecto da variação social, já que não se pode conceber a língua sem uma sociedade que a use. Como todo tipo de preconceito, o que ocorre é a seleção e a valorização (sem fundamento) de uma variedade em detrimento às demais. Para melhor explicar esse ponto, vejamos o que diz Lucchesi (2015, p. 18):
Os fatores sociais atuam como um importante mecanismo de reforço e sedimentação dos mitos, estereótipos, dogmas e preconceitos que plasmam a visão hegemônica de língua na sociedade. E nem mesmo o advento, nas últimas décadas, da nova era da informação, produzida pela terceira revolução industrial, alterou esse estado de coisas.

É importante destacar o fato de termos disseminado na sociedade brasileira uma ideologia da língua padrão, culta, correta que avalia todas as demais variedades linguísticas como incorretas. Com a citação acima, os fatores sociais ajudam a naturalizar essa ideologia e, consequentemente, reforçam os dogmas, os preconceitos em torno da língua. Aos olhos do pesquisador, no entanto, fica claro que as avaliações das variedades linguísticas não são intrínsecas a elas, mas é "o resultado da avaliação social impingida aos seus usuários” (LUCCHESI, 2015, p. 20).

Mesmo não tendo sustentação empírica e consistência teórica, a ideologia da língua correta está enraizada no senso comum por uma cultura milenar. No caso do Brasil, isso ocorre desde o processo de formação da nacionalidade, no século XIX. Assim, a ideologia de uma língua única, correta, advém das representações que estão na base da construção simbólica da nacionalidade.

Diante disso, não é raro constatamos discursos que reproduzem uma polarização sociolinguística no território brasileiro. De um lado, elegem a norma sociolinguística da elite letrada, a língua correta, e, de outro lado, colocam a norma da população socialmente marginalizada, menos prestigiada.

Nesse ponto, é importante destacarmos o papel do LD na reprodução e naturalização de discursos preconceituosos, ou, ao contrário, seu papel no processo de conscientização da existência da diversidade linguística, no sentido de fazer saber a equidade entre as variantes linguísticas e suas importâncias na formação identitária do Brasil. Assim, na próxima seção, 
analisaremos o LD referente ao sexto ( $\left.6^{\circ}\right)$ ano, mostrando como esse recurso didático trabalha o ensino da variação linguística.

\section{As variedades linguísticas no LD de Português: Linguagens}

Considerando que este trabalho tem como propósito analisar uma proposta de ensino das variedades linguísticas no LD utilizado pelos professores para mediar sua prática educativa em sala de aula, passaremos a analisar a proposta do LD Português: Linguagens, dos autores William Roberto Cereja e Thereza Cochar Magalhães, da editora Atual, 2009, especificamente o volume trabalhado no 6으 (sexto) ano do Ensino Fundamental II. Analisaremos as seções de formulações conceituais e, em seguida, duas atividades destinadas ao tratamento da variação linguística.

\section{Fragmento 01}

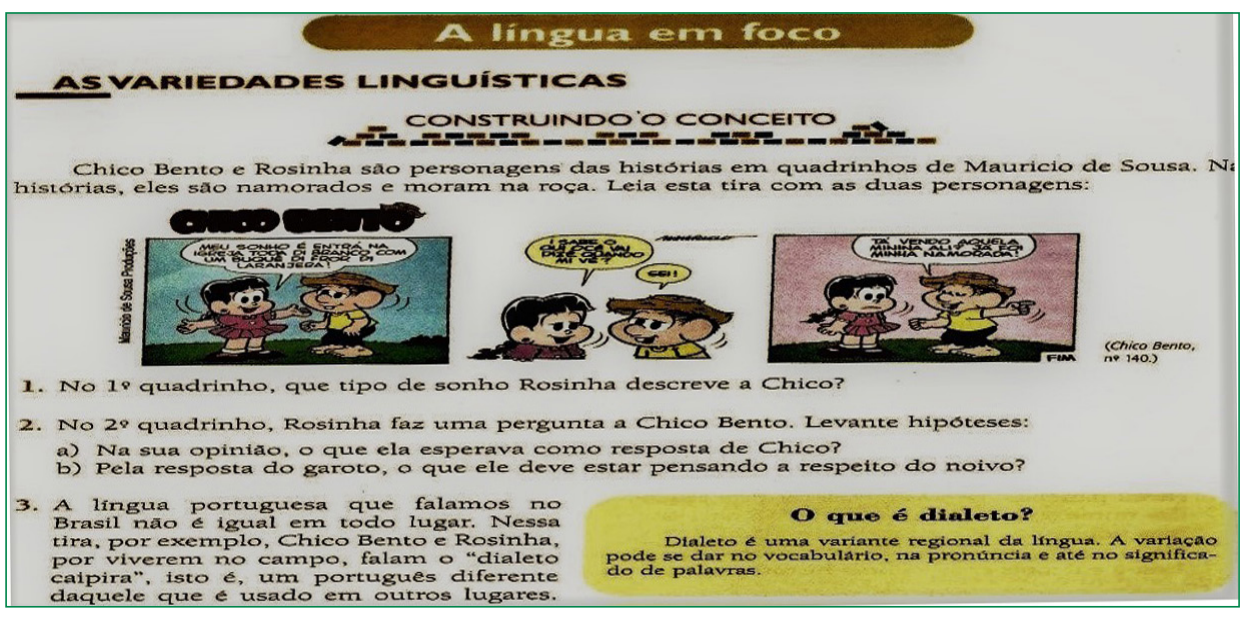

LD do 6ㅇa ano (CEREJA e MAGALHÃES, 2009, p. 44).

Percebe-se, no Fragmento 01, que os autores reservam um boxe para conceituar dialeto, tratando, por sua vez, de forma coerente, o seu posicionamento ao dizer que: “Dialeto é uma variante regional da língua. A variação pode-se dar no vocabulário, na pronúncia e até no significado de palavras" (CEREJA e MAGALHÃES, 2009, p. 44). Como exemplo, os autores destacam uma tirinha do personagem Chico Bento, de Maurício de Souza, na qual se notam variedades linguísticas presentes no diálogo entre os personagens Chico Bento e Rosinha.

Diante disso, como mostra Bagno (2008), observa-se uma grande tendência dos autores a tratar da variação linguística como sinônimo de variedades regionais ou rurais, trazendo, geralmente, como exemplificação, as tirinhas do personagem Chico Bento, como se apenas no falar 'caipira' ocorresse o fenômeno da variação. Consequentemente, esse tratamento causará nos alunos uma visão equivocada de que somente pessoas das zonas rurais e não-escolarizadas fazem uso destas variedades linguísticas.

Percebemos, assim, de forma velada, "o estigma sobre as variedades de língua das populações pobres, excluídas do universo superior do letramento", conforme nos diz Lucchesi (2015, p. 18). Em outros termos, ao polarizar a sociedade e a língua, o LD atua, de forma decisiva, na construção de uma cosmovisão estratificada e rigidamente hierarquizada, naturalizando as relações de dominação política e de exploração econômica.

Ao criar uma identidade 'caipira' para quem usa certa variedade da língua, entendemos, em consonância com Moita Lopes (2013), que a ideologia da língua padrão constrói identidades, preconceitos, estigmas, já que polariza a língua em certo X errado, padrão X não padrão, culto X 'caipira'.

Ao mesmo tempo, a estratégia ideológica de rotular certos usos como 'caipira', não é apenas uma avaliação da língua, mas, principalmente, dos usuários. Milroy (2011, p. 53) nos lembra de que “[...] não é difícil argumentar que as variedades de língua realmente não têm prestígios em si mesmas: tais variedades adquirem prestígio quando seus falantes têm prestígio elevado". 
Com isso, ele ressalta o fato de que o prestígio e o estigma são construídos socialmente, ou seja, eles são atribuídos, pelos indivíduos, aos grupos sociais e aos objetos. Nessa linha de pensamento, o autor explica que "o prestígio atribuído às variedades linguísticas (por metonímia) é indexador e está envolvido na vida social dos falantes" (MILROY, 2011, p. 53).

Vejamos mais detalhes da proposta do LD.

\section{Fragmento 02}

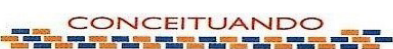

Mauricio de Sousa, quando criou a personagenn Chico Bento, imaginou tudo o que caracteriza
um menino que vive na roca, descle o seu jeito de viver com a familia e com os amigos ate a lingua
que fala.

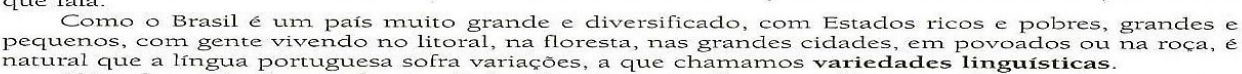

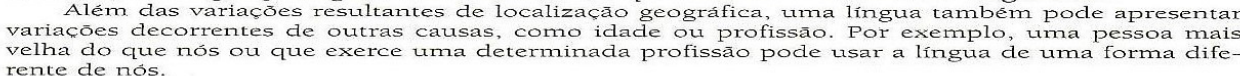
Variedades linguisticas são as variaçōes que uma lingua apresenta em razão das condi-
çôes sociais, culturais e regionais nas quais e urilizada.

Língua padrão: a variedade de prestígio social

Todas as variedades lingursticas são eficazes na comunicacão e possuem valor nas comunida-
des em que são faladas. Apesar disso, existe entre as variedades uma que tem maior prestigio ocial, pois e utilizada em livros, documentos, cartas comerciais, jornais, revistas, programas de tevê e por pessoas que tiveram mais acesso
aos estudos: e a lingua padrāo, tambem conhecida como variedade padrão ou
norma culta. Essa variedade linguística é necessária
em diferentes momentos de nossa vida social: ao fazermos uma entrevista para consegui
um emprego, ao apresentarmos um trabalho escolar, ao participarmos de um debate, ao da prefeitura, ao fazermos um requerimento etc. Dada sua importanncia, a escola se propóe a ensinar a variedacle padrão a todas as crian-
cas e jovens do pais, preparando-os para

Acesso à língua padrão:
questão de cidadania?

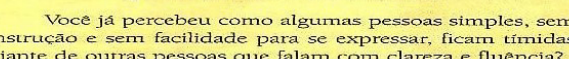
instrucaa e sem facilidade para se expressar, ficarn tirniclas
diante de outras pessoas aue falam com clareza e fluencia? meio dela náo é um privilegio de poucos. Ao contrario, padrão, colocamo-nos em pé de igualidade lingustictica com

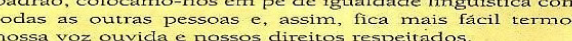

Língua padrão. norma culta ou variedade padrão é a variedade linguistica de maior prestifio social.
Lingua não padrão é o conjunto de todas as variedades linguisticas diferentes da lingua padrão.

Falar bem é falar adequadamente

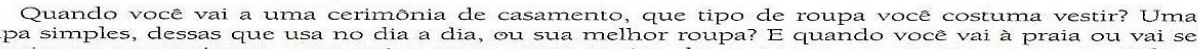

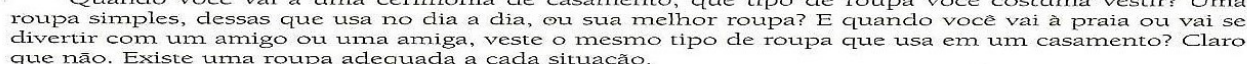
que
Falar umna língua é parecido conn vestir-se: assim como existe uma roupa adequada para cada
situracano, existe tamberm uma variedade linguística adequada para cada situacăo.

LD do 6o ano (CEREJA e MAGALHÃES, 2009, p. 45)
No Fragmento 02, os autores do LD evidenciam que a Língua Portuguesa é composta por diversas variedades e estas são condicionadas por fatores sociais, culturais e regionais. Além disso, assumem pressupostos adotados pela Sociolinguística, quando afirmam que: "Todas as variedades linguísticas são eficazes na comunicação e possuem valores nas comunidades em que são faladas" (CEREJA e MAGALHÃES, 2009, p. 45). Pode-se também perceber que os autores têm a preocupação de mostrar que adequamos nossa fala de acordo com determinadas situações de interação comunicativa, já que, segundo eles, "existe também uma variedade linguística adequada para cada situação” (CEREJA e MAGALHÃES, 2009, p. 45).

De modo particular, quando o autor aponta para a questão de "falar adequadamente", podemos também compreender, de modo positivo, que essa adequação está além de um posicionamento relacionado apenas à variedade de prestígio, a língua padrão. Essa adequação é estabelecida pelas diversas condições sociais que determinam a maneira de falar do sujeito e isso é algo que está totalmente exterior à estrutura da língua, a saber: são questões de ordem econômica, geográfica, histórica, ideológica, cultural, dentre outras. Como afirma Bortoni-Ricardo (2005), o prestígio da variedade padrão, em nossa terminologia, "adequada", não se restringe aos grupos de usuários, mas vai além de todos os seguimentos sociais. Ainda, como aponta BortoniRicardo ( 2005, p. 14), “o cidadão erudito aprecia a língua culta, que por sinal é seu meio natural de comunicação, mas o trabalhador braçal, a empregada doméstica, os milhões de iletrados também o fazem".

Além disso, de mono menos positivo, é possível notar certa avaliação das variedades linguísticas por parte dos autores do LD. Ao utilizar a ilustração das vestes 'falar uma língua é parecido com vestir-se', os autores deixam escapar que a roupa usada em um casamento é a 'melhor'. Logo, aplicando isso às variedades, existe uma variedade melhor do que as outras. As variedades não padrão são rotuladas de 'simples'. Ora, se formos levar a 
comparação a sério, podemos concluir que, da mesma forma que aqueles que não têm uma roupa boa não podem ir a um casamento, quem não tem o domínio da norma padrão está excluído de certos eventos sociais. Aqui, a norma padrão é um bem simbólico, garantia de ascensão social.

Isso pode ser corroborado ao analisarmos o comentário da página, intitulado Acesso à língua padrão: questão de cidadania que diz: "ter acesso à língua padrão e saber se expressar por meio dela não é um privilégio de poucos. Ao contrário, é um direito de todo cidadão. Apropriando-nos da língua padrão, colocamo-nos em pé de igualdade linguística com todas as outras pessoas e, assim, fica mais fácil termos nossa voz ouvida e nossos diretos respeitados". Assim, o LD ressalta a importância da língua padrão em comparação com as outras variedades da língua, já que é por meio da aquisição da língua padrão que é possível se expressar bem para fazer ouvir a voz e garantir direitos. Essa ideologia da língua padrão, já cristalizada nos discursos do cotidiano, do senso comum, diz, ainda, que a língua correta e boa não está no domínio dos usuários mais carentes, essa língua precisa ser dada a eles como garantia de direitos e de ascensão social.

Ademais, constatamos que as atividades propostas pelo LD se limitam às variedades rurais e/ou regionais, polarizando a discussão acerca das variedades linguísticas. Vejamos a primeira atividade no Fragmento 03, ao lado:

Observamos, nessa atividade, mais especificamente nas questões 3 e 5, que os autores procuram enfatizar os diversos modos de falar de um indivíduo de acordo com sua localização geográfica, tendo como objetivo mostrar aos alunos que existem formas alternadas de se falar determinadas palavras.

Diante de questões como estas, o professor poderia mostrar aos seus alunos que a língua sofre variações, decorrentes de diversos fatores extralinguísticos, tais como: idade, profissão, sexo, localização geográfica, classe social, entre outros (LABOV, 2008). Assim, estariam demonstrando que essa variação na fala é um uso sistemático e regular de uma propriedade inerente aos sistemas linguísticos.

\section{Fragmento 03}

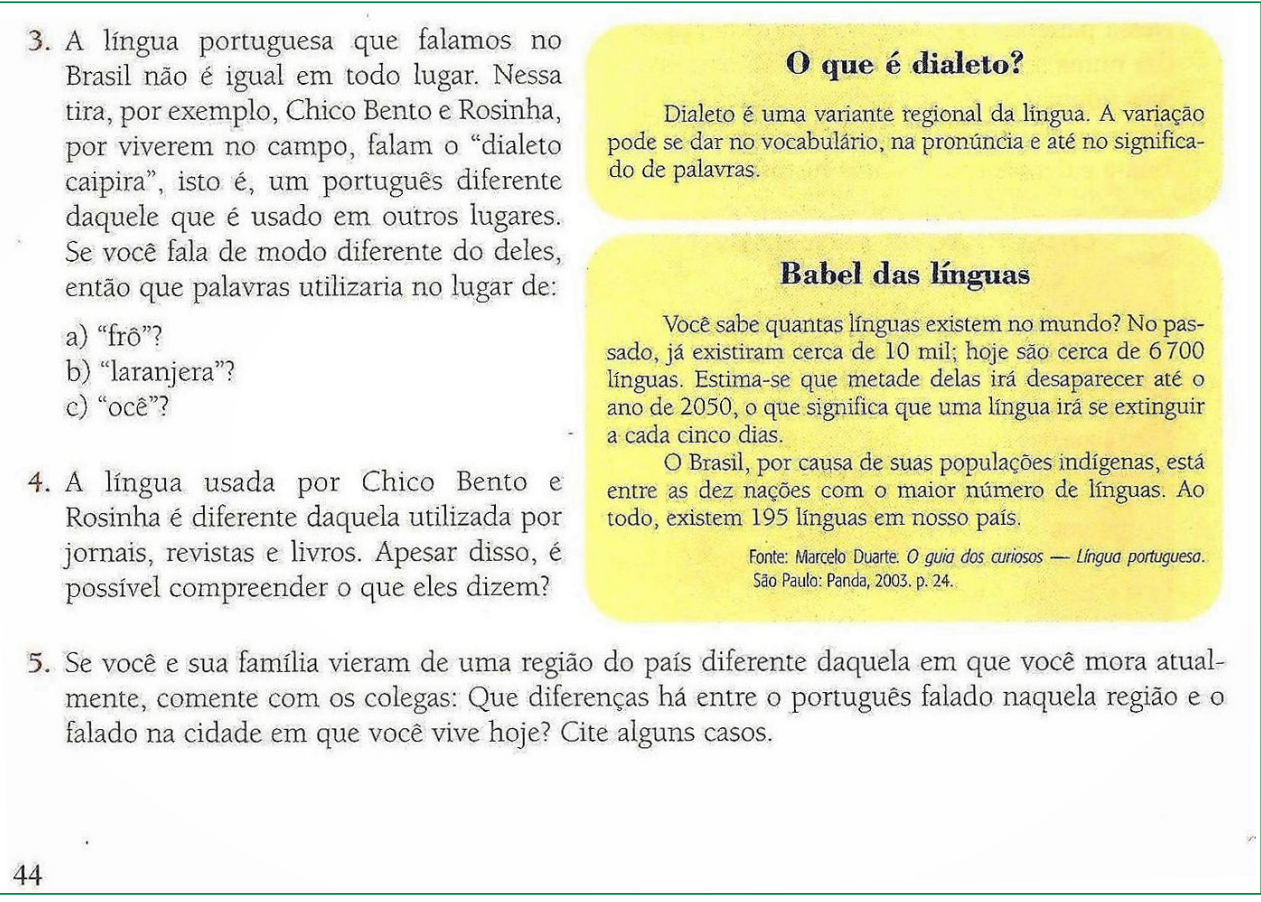

LD do 6ํano (CEREJA e MAGALHÃES, 2009, p. 44).

Fora isso, pode-se perceber, na questão 4 da atividade, que os autores tentam conscientizar os alunos para o fato de que, apesar da existência de muitas variantes para referir-se a uma determinada variável, estas não deixam de transmitir o mesmo valor de verdade, já que produzem o mesmo sentido, não interferindo assim na sua compreensão. 


\section{Fragmento 04}

3. Há, no poema, várias palavras que não correspondem à variedade padrão escrita. Identifique essas formas indique quais seriam as formas correspondentes a elas na variedade padrão escrita.

4. Alguns desvios da variedade padrão têm base numa certa lógica. Coloque-se no papel de um linguista (profissional especializado em linguagem) e tente explicar os desvios que seguem. Primeiramente. observe e compare estes casos:

$$
\begin{array}{lll}
\text { lavá } & \text { trabaiá } & \text { os zóio } \\
\text { abri } & \text { zóio } & \text { as água }
\end{array}
$$

a) Em algumas variedades não padrão, a letra -r do final de algumas palavras terminadas em -ar, -er e -ir desaparece, como ocorreu em lavá, trabaiá, luá e abri. Na sua opinião, por que isso acontece?

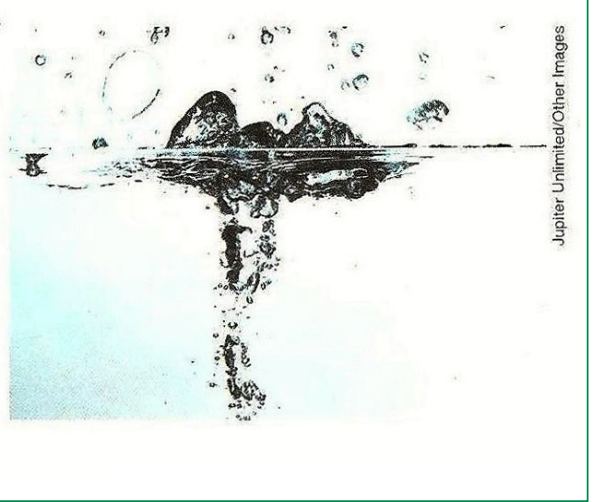

LD do 6ำ ano (CEREJA e MAGALHÃES, 2009, p. 48)

No exercício desse Fragmento 04, Cereja e Magalhães pedem, na questão 3, que os alunos identifiquem, no poema de Sérgio Capparelli, as palavras que não correspondem à variedade padrão escrita e depois indiquem as formas correspondentes a elas na variedade padrão escrita. Diante disso, percebemos um problema no tratamento das variedades linguísticas, pois, ao pedirem para os alunos identificarem as variedades estigmatizadas e transformá-las em variedades prestigiadas, além de não demonstrarem respeito pelo gênero textual, acabam conduzindo ao entendimento de que, ao final das contas, o que vale realmente são as variedades socialmente prestigiadas, e as demais são inaceitáveis no sistema linguístico, adotando, assim, o modelo da deficiência verbal.

Aqui a língua padrão é um bem que precisa ser adquirido para o sujeito poder se dar bem. Essa é uma crença que perpassa as sociedades de cultura padrão. Essa crença está fundamentada no princípio da existência de uma língua padrão que unifica e identifica os falantes. Essa crença, no entanto, é responsável pela distorção do pensamento acerca da natureza da língua/ linguagem. Quando se postula uma dicotomia entre padrão e não padrão, no entender de Milroy (2011, p. 56), "os dialetos se tornam, por assim dizer, satélites que têm órbitas em distância variadas em torno de um corpo central - o padrão."

Ainda nesse fragmento, notamos, na questão 4, dois equívocos. No primeiro, os autores referem-se ao fenômeno da variação como desvios da variedade padrão, quando, na verdade, a variação não é o resultado do uso arbitrário e irregular dos falantes, pois esta é motivada por fatores linguísticos e extralinguísticos e obedecem a sistematicidade e a regularidade do sistema linguístico em uso (LABOV, 2008; TARALLO, 2007).

$\mathrm{O}$ segundo equívoco diz respeito à eliminação do - $\mathrm{R}$ final nos infinitivos e, também, em outras palavras, que os autores consideram como marca típica de variedades não padrão. No entanto, o apagamento do -R em final de palavras "[...] é um traço característico de todas as variedades linguísticas brasileiras, independentemente da região ou da classe social do falante [...]" (BAGNO, 2007, p.121). Portanto, torna-se incoerente considerar esse fenômeno linguístico pertencente somente aos usos de falantes rurais, não escolarizados e pobres.

Caminhando para as conclusões desse trabalho, é possível notar, portanto, que o modo como a variação linguística é ensinada no LD corrobora o pressuposto da tradição normativa que coloca o ensino da norma-padrão como compensador de supostas carências socioculturais. Em decorrência desse pressuposto, podemos perceber que uma das tarefas do ensino é substituir a variedade não-padrão pela padrão. Criticando essa postura, a Sociolinguística se apresenta propondo uma alternativa fundamental, segundo a qual variações de linguagem não devem passar por um crivo 
valorativo, já que não são mais que formas alternativas que o sistema linguístico põe à disposição do falante.

\section{Conclusão}

Este trabalho foi desenvolvido a partir, primeiro, de uma revisão bibliográfica de alguns conceitos sociolinguísticos e, segundo, da análise de um LD, objetivando perceber como LD Português: Linguagens, dos autores William Roberto Cereja e Thereza Cochar Magalhães, trabalha a variação linguística. Mais precisamente, pautamos nossa análise em uma proposta de ensino de variação linguística de um livro direcionado aos alunos do sexto (6ㅇ) ano do ensino fundamental. Ao trilharmos esse percurso, dialogamos, entre outros, com estudos de Labov (2008), Bagno (2008), Lucchesi (2015), Milroy (2011), Moita Lopes (2013), Hernández e Almeida (2005).

A proposta analisada, apesar de apresentar questões de variação linguística, tais como, conceitos e alguns exemplos, deixa a desejar em vários aspectos. Notamos que as variedades da língua são utilizadas para ensinar ao aluno como corrigir um determinado uso. Nesses casos, o LD assume a norma padrão da língua e, a partir dela, conceitua as demais como sendo desprestigiadas, vulgares e caipiras. Esse tratamento, evidentemente, reproduz e fortalece preconceitos sociais e linguísticos, já que reproduz, sem questionamentos, certos paradigmas, naturalizando, assim, a polarização sociolinguística (LUCCHESI, 2015).

É interessante notar, ainda, que a temática da variação linguística é apresentada a partir do argumento da comparação. No caso, toma-se a língua culta, falada por pessoas cultas, prestigiadas, e a compara com uma variedade caipira, do campo, falada por pessoas analfabetas, simples. Essa seleção, por si só, produz uma imagem distorcida da variação linguística, já que ela não diz respeito a apenas a esses dois polos sociais.
Ademais, fica clara a força da ideologia da língua padrão em criar uma imagem de língua da elite, língua dos lugares e momentos requintados, língua que garante a aquisição de bens simbólicos (status social, por exemplo). Ao apresentar as vantagens de adquirir essa língua, de forma velada, o LD passa a incentivar a correção e adequação de todas as outras variedades linguísticas a essa norma. Isso é percebido nos exercícios e nos comentários feitos pelos autores do livro.

No entanto, cabe esclarecer que não desconsideramos a função e o uso da norma padrão. É legítimo o uso que se dá a norma padrão em situações formais, mas isso, quando a situação exigir, pois é uma opção que está disponível para o falante. Mas isso não deve nos levar ao ponto de considerar errado todas as outras variedades que fogem a essa norma. O problema aqui, portanto, é com as atitudes diante da diversidade sociolinguística. 0 comentário de Bagno (2007, p. 37) é pertinente para explicar esse nosso entendimento:

O verdadeiro problema é considerar que existe uma língua perfeita, correta, bem acabada e fixada em bases sólidas, e que todas as inúmeras manifestações orais e escritas que se distanciem dessa língua ideal são como ervas daninhas que precisam ser arrancadas do jardim para que as flores continuem lindas e coloridas.

Compartilhando das palavras do autor, entendemos que não existe uma língua perfeita em detrimento a outras (imperfeitas). Na verdade, existem condições sociais que são características imprescindíveis para que o sujeito possa falar "adequadamente" em cada situação social. Desse modo, o "uso (in)correto" da língua será feito a partir da exigência de uma variação adequada para um dado contexto social. Portanto, na língua, sempre vai haver variações e nós, enquanto sociedade, é que temos que nos adequar a essas diferentes situações, pois não há modo de falar errado ou mais bonito que outro. 
Por fim, mesmo com as limitações constatadas, deve-se destacar a proposta apresentada pelo LD, que visa evidenciar a existência de variedades linguísticas e direcionar o ensino de língua para essa realidade. Assim, já que, na condição de recurso didático, o LD apresenta limitações, cabe ao professor expandir a proposta desse material didático, trazendo para o ensino de língua portuguesa as variedades linguísticas que constituem a realidade cultural brasileira. Como bem ressalta Faraco (2008), a língua é heterogênea. Ela é o próprio conjunto de variedades e expressa a diversidade sociocultural que existe no país.

Para o trabalho com a heterogeneidade linguística no ensino de língua cabe considerar as discussões advindas dos estudos sociolinguísticos, que nos fazem pensar no tratamento dos fatos de linguagem a partir de elementos linguístico-sociais capazes de formar, no sujeito-falante, uma consciência linguística, bem como uma identidade linguística formada pela soma de fatores que envolvem o sujeito e as convenções histórico-sociais de sua comunidade de fala.

\section{Referências}

ANTUNES, I. Muito além da gramática: por um ensino de língua sem pedras no caminho. São Paulo: Parábolas, 2007.

BAGNO, M. Nada na língua é por acaso: por uma pedagogia da variação linguística. São Paulo: Parábola Editorial, 2007.

Preconceito linguístico: o que é, como se faz. 50. ed., São Paulo: Loyola, 2008.

BORTONI-RICARDO, Stella Maris. Nós chegamos na escola e agora? São Paulo: Parábola, 2005.

FERnÁNDEZ, F. M. Principios de Sociolinguística y Sociología del lenguaje. Barcelona: Ariel, 1998.

FARACO, C. A. Norma culta brasileira: desatando alguns nós. São Paulo: Parábola Editorial, 2008
HERNÁNDEZ, J. M.; ALMEIDA, M. Metodología de la investigación sociolinguística. Granada: Comares, 2005.

LUCCHESI, D. Língua e sociedade partidas: a polarização sociolinguística do Brasil. São Paulo: Contexto, 2015

LABOV, W. Padrões Sociolinguísticos. São Paulo: Parábolas, 2008.

MILROY, J. Ideologias linguísticas e as consequências da padronização. In: LAGARES, X. C.; BAGNO, M. Políticas da norma e conflitos linguísticos. Tradução de Marcos Bagno. São Paulo: Parábola Editorial, 2011. p. 49-87.

MOITA LOPES, Luiz Paulo. Ideologia linguística: como construir discursivamente o português no século XXI. In: MOITA LOPES, L. P. (Org.). Português no século XXI: cenário geopolítico e sociolinguístico. São Paulo: Parábola Editorial, 2013. p. 18-52.

TARALLO, F. Pesquisa sociolinguística. 8. ed. São Paulo: Ática, 2007.

Recebido em 20/08/2016

Aceito em 04/01/2017. 